\title{
Effects of castration and hormone replacement on Sidman avoidance acquisition in the rat
}

\author{
E. D. HAMLIN and DAVID M. McCORD \\ Department of Psychology \\ GARY L. POOL \\ Department of Chemistry \\ and \\ JOEL S. MILNER \\ Department of Psychology \\ Western Carolina University, Cullowhee, North Carolina 28723

\begin{abstract}
The effects of castration and hormone replacement on the acquisition of a leverpress Sidman avoidance task were examined. Sixty male rats were assigned randomly to one of five groups: (1) castration with estradiol treatment, (2) castration with progesterone treatment, (3) castration with estradiol and progesterone treatment, (4) castration with saline treatment, and (5) sham castration with saline treatment. Serum hormone concentrations were determined by radioimmunoassay. While serum assays indicated an increase of at least $600 \%$ to $3,300 \%$ for progesterone and estrogen levels, respectively, the results did not reveal any significant castration or hormone effects on the acquisition of the avoidance task.
\end{abstract}

As previously noted (McCord, Hamlin, Pool, \& Milner, 1979), gender differences have been reported for numerous nonreproductive behaviors (Barrett \& Ray, 1970; Beatty \& Beatty, 1970; Broverman, Klaiber, Kobayashi, \& Vogel, 1968; Davis, Porter, Burton, \& Levine, 1976; Denti \& Epstein, 1972), and the gonadal hormones have been suggested as mediators of the observed differences. Although many physiological factors may influence sex differences, investigators (Beatty, 1973; McCord, Hamlin, Pool, \& Milner, 1979; Lentz, Pool, \& Milner, 1978; Milner, 1976) have provided evidence of gonadal effects on DRL and Sidman avoidance behavior. Research has shown castration effects on the acquisition of DRL (Beatty, 1973) and Sidman avoidance (Milner, 1976) tasks. However, investigators employing hormone replacement techniques have reported only trends in hormone-related facilitation of DRL (Lentz et al., 1978) and Sidman avoidance (McCord et al., 1979) tasks. The data suggest improved acquisition in estrogen-treated animals. The purpose of the present study was to provide additional information on the effects of castration and hormone replacement on the acquisition of a Sidman avoidance task.

The authors wish to thank Robbie Smeltzer for valuable assistance with the radioimmunoassays. Send reprint requests to Joel S. Milner, Department of Psychology, Western Carolina University, Cullowhee, North Carolina 28723.

\section{METHOD}

\section{Subjects}

Sixty naive male rats (Holtzman strain) served as the subject pool for the experiment. The animals arrived in the laboratory at 117 days of age. The animals were individually housed in 17 by 25 by $17 \mathrm{~cm}$ stainless steel cages throughout the experiment. The laboratory was temperature controlled. Except for the training period, food and water were available ad lib.

\begin{abstract}
Apparatus
A standard operant conditioning chamber with an electrifiable grid floor and a single stainless steel barpress was used to determine acquisition rates. The operant chamber was controlled by Coulbourn solid state programming modules, and a GrasonStadler shock generator provided the shock. The number of shocks and responses for the task were recorded on 12 digital counters (bins). Ten of the bins were stepped at the rate of 1 per 2 sec to record the interresponse interval. The two additional bins recorded total shocks and total responses. Shocks and responses were also recorded on a Gerbrands cumulative recorder.
\end{abstract}

\section{Procedure}

Animals were assigned randomly to one of five treatment groups, the only restriction being that each group contain an equal number of animals $(n=12)$. Groups were (1) castration with estradiol treatment $(\mathrm{E})$, (2) castration with progesterone treatment (P), (3) castration with estradiol and progesterone treatment (EP), (4) castration with saline treatment $(\mathrm{Cx})$, and (5) sham castration with saline treatment (Sh). Animals were randomly assigned to a surgery schedule that allowed for equating of time from surgery to training period. At 124-138 days of age, animals were anesthetized for approximately $10 \mathrm{~min}$ with ether and either castrated $(n=48)$ or sham castrated $(n=12)$; 
26 days postoperative recovery was permitted for each animal. Upon recovery from surgery, one intraperitoneal injection of drug or saline was given each animal for 8 consecutive days. Crystalline hormones were dispersed in normal saline at a concentration of $20 \mathrm{mg} / \mathrm{cc}$. Animals in Groups $E$ and $P$ received $.5 \mathrm{cc}$ of estradiol and progesterone, respectively, plus $.5 \mathrm{cc}$ of saline, resulting in a daily dosage of $10 \mathrm{mg}$ of hormone dispersed in a volume of $1 \mathrm{cc}$. Animals in Group EP received daily injections of $.5 \mathrm{cc}$ of estradiol dispersion plus $.5 \mathrm{cc}$ of progesterone dispersion, resulting in $10 \mathrm{mg}$ of each hormone in a total volume of $1 \mathrm{cc}$. Animals in Groups $\mathrm{Cx}$ and $\mathrm{Sh}$ were given daily injections of $1 \mathrm{cc}$ of normal saline.

A period of $15 \mathrm{~min}$ prior to being placed in the operant chamber, each animal was administered the eighth, and last, injection. The Sidman avoidance program was begun as soon as the animal was placed in the operant chamber. The program delivered a shock $(1 \mathrm{~mA}$ for $.5 \mathrm{sec})$ every $5 \mathrm{sec}$ (shock-shock interval $=5 \mathrm{sec}$ ) unless the animal pressed the bar, at which time the next shock was delayed for $20 \mathrm{sec}$ (response-shock interval = $20 \mathrm{sec}$ ). Acquisition sessions lasted $2 \mathrm{~h}$ without interruption. A criterion of 50 or fewer responses/h was employed to exclude "nonlearners" from the experiment.

\section{Blood Assays}

At the conclusion of the 2-h training session, each animal was removed from the operant chamber and anesthetized with ether. A 1- to 2-cc sample of blood was drawn by cardiac puncture. The blood was allowed to coagulate at $4^{\circ} \mathrm{C}$ for a minimum of $24 \mathrm{~h}$. Radioimmunoassays were performed on a blind basis for each sample to determine levels of estradiol and progesterone.

\section{RESULTS}

Seven animals failed to make the criterion of 50 responses/h during the 2-h acquisition session and were deleted from the analysis. Three of the animals designated as "nonlearners" were from Group EP, two from Group E, and one each from Groups $P$ and Sh.

The mean number of shocks received and responses emitted are presented in Tables 1 and 2, respectively. A one-way analysis of variance did not reveal a significant difference between groups in shocks received $[F(4,48)=2.38, p>.05]$. However, another analysis of variance did show a significant difference in responses emitted $[F(4,48)=3.65, p<.05]$. A Student NeumanKeul's comparison of group response rates revealed that progesterone-treated animals emitted significantly higher $(p<.05)$ response rates than estradiol-treated and shamtreated animals. The groups by bins analysis yielded a significant bin effect $(p<.01)$, as well as a significant

Table 1

Mean Number of Shocks Received During a 2-H Sidman Avoidance Acquisition Session

\begin{tabular}{lrrr}
\hline \multicolumn{1}{c}{ Groups } & N & Mean & SE \\
\hline Castrated, Estradiol & 10 & 265 & 120 \\
Castrated, Estradiol plus Progesterone & 9 & 171 & 50 \\
Castrated, Progesterone & 11 & 155 & 83 \\
Castrated, Saline & 12 & 199 & 62 \\
Sham Castrated, Saline & 11 & 221 & 87 \\
\hline
\end{tabular}

Table 2

Mean Number of Responses Emitted During a 2-H Sidman Avoidance Acquisition Session

\begin{tabular}{lrrr}
\hline \multicolumn{1}{c}{ Groups } & N & Mean & SE \\
\hline Castrated, Estradiol & 10 & 974 & 359 \\
Castrated, Estradiol plus Progesterone & 9 & 1252 & 262 \\
Castrated, Progesterone & 11 & 1383 & 335 \\
Castrated, Saline & 12 & 1158 & 280 \\
Sham Castrated, Saline & 11 & 982 & 251 \\
\hline
\end{tabular}

Group by Bin interaction $(\mathrm{p}<.01)$. Simple effects analysis revealed that interaction was due primarily to differences in Bin $1(0-2 \mathrm{sec})$.

\section{Blood Assays}

Progesterone levels averaged $271 \mathrm{ng} / \mathrm{ml}$ of blood for Group P $(n=11)$ and $173 \mathrm{ng} / \mathrm{ml}$ for Group EP $(\mathrm{n}=9)$, whereas in all other groups, the average progesterone level was $28 \mathrm{ng} / \mathrm{ml}(\mathrm{n}=33)$. Blood levels of estradiol averaged $142 \mathrm{ng} / \mathrm{ml}$ for Group E $(\mathrm{n}=10), 134 \mathrm{ng} / \mathrm{ml}$ for Group EP $(\mathrm{n}=9)$, and $4 \mathrm{ng} / \mathrm{ml}$ for all other groups $(n=34)$.

\section{DISCUSSION}

Previous research has reported significant castration effects on the acquisition of DRL (Beatty, 1973) and Sidman avoidance (Milner, 1976) tasks. In hormone replacement studies, investigators have observed consistent, albeit nonsignificant, trends toward estradiol facilitation of acquisition (Lentz et al., 1978; McCord et al., 1979; Beatty, Note 1). The present study did not reveal any significant differences between treatment groups. That is, neither castration nor drug injections affected acquisition. Estradiol facilitative trends were not present.

The failure to observe castration effects may be due to strain differences. In the previous report (Milner, 1976) where significant castration effects were reported, Wistar rats were employed, whereas Holtzman rats were used in the present study.

While conducting the present experiment, an attempt was made to equate hormonal dosages with the McCord et al. (1979) study, which reported trends toward estradiol facilitation of Sidman avoidance acquisition. The attempt failed. In the current study, assays revealed hormone-treated animals displayed a $200 \%$ to $300 \%$ increase in hormone serum levels when compared to the McCord et al. (1979) study. Thus, differences in reported estradiol effects on acquisition may result from dose-response effects. Investigations should be undertaken to explore the possible existence of an estrogen dose-response curve. The variation in assay results from studies using similar procedures also suggests that comparisons between studies not including blood assays are tenuous.

\section{REFERENCE NOTE}

1. Beatty, W. W. Personal communication, 1978.

\section{REFERENCES}

BARRETT, R. J., \& RAY, O. S. Behavior in the open field, Lashley III maze, shuttle-box, and Sidman avoidance as a function of strain, sex, and age. Developmental Psychology, 1970, 3, 73-77. 
BeAtTy, W. W. Effects of gonadectomy on sex differences in DRL behavior. Physiology \& Behavior, 1973, 10, 177-178.

Beatty, W. W., \& Beatty, P. A. Hormonal determinants of sex differences in avoidance behavior and reactivity to electric shock in the rat. Journal of Comparative and Physiological Psychology, 1970, 73, 446-455.

Broverman, D. M., Klaiber, E. L., Kobayashi, Y., \& Vogel, W. Roles of activation and inhibition in sex differences in cognitive abilities. Psychological Review, 1968, 75, 23-50.

Davis, H., Porter, J. W., Burton, J., \& Levine, S. Sex and strain differences in leverpress shock escape behavior. Physiological Psychology, 1976, 4, 351-356.

Denti, A., \& Epstein, A. Sex differences in the acquisition of two kinds of avoidance behavior in rats. Physiology \& Behavior, $1972,8,611-615$

Lentz, F. E., Pool, G. L., \& Milner, J. S. Effects of ovariectomy and hormone replacement on DRL behavior in the rat. Physiology \& Behavior, 1978, 20, 477-480.

McCord, D. M., Hamlin, E. D., Pool, G. L., \& Milner, J. S. Castration, gonadal hormones and Sidman avoidance acquisition. Physiology \& Behavior, 1979, 22, 601-603.

Milner, J. S. Castration and amphetamine effects on acquisition of a Sidman avoidance task in rats. Physiology \& Behavior, 1976, 17, 545-548.

(Received for publication May 13, 1979.)

\section{ERRATUM}

Capaldi, E. D., \& Myers, D. E. Resistance to satiation as a function of three satiation procedures. Bulletin of the Psychonomic Society, 1979, 14 (1), 53-56. Page 53, the last sentence of the abstract should read: These results are partially consistent with an associative interpretation that assumes that resistance to satiation of eating and running is greater the higher the proportion of cues present in satiated testing that had been conditioned in acquisition. 